\title{
Article
}

\section{The infamous story of incident stroke and inflamed gall bladder!}

Srivastava, M V Padma and Vishnu, V Y

Available at http://clok.uclan.ac.uk/28668/

Srivastava, M V Padma and Vishnu, VY (2019) The infamous story of incident stroke and inflamed gall bladder! Neurology India, 67 (2). pp. 389-390. ISSN 0028-3886

It is advisable to refer to the publisher's version if you intend to cite from the work. http://dx.doi.org/10.4103/0028-3886.258025

For more information about UCLan's research in this area go to

http://www.uclan.ac.uk/researchgroups/ and search for <name of research Group>.

For information about Research generally at UCLan please go to http://www.uclan.ac.uk/research/

All outputs in CLoK are protected by Intellectual Property Rights law, including Copyright law. Copyright, IPR and Moral Rights for the works on this site are retained by the individual authors and/or other copyright owners. Terms and conditions for use of this material are defined in the policies page.

\section{CLoK}

Central Lancashire online Knowledge www.clok.uclan.ac.uk

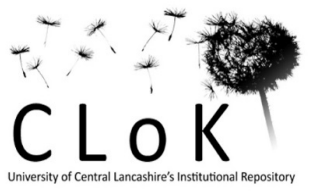




\section{NEUROLOGY INDIA}

\section{Publication of the Neurological Society of India}

\section{NI FEATURE: THE EDITORIAL DEBATE I-- PROS AND CONS}

Year : 2019 | Volume : 67 | Issue : 2 | Page : 389--390

\section{The infamous story of incident stroke and inflamed gall bladder!}

M V Padma Srivastava ${ }^{1}$, VY Vishnu²,

${ }^{1}$ Department of Neurology, All India Institute of Medical Sciences, New Delhi, India; Department of Neurology, University of Central Lancashire, United Kingdom

2 Department of Neurology, All India Institute of Medical Sciences, New Delhi, India

\section{Correspondence Address:}

Dr. M V Padma Srivastava

Department of Neurology, All India Institute of Medical Sciences, New Delhi

How to cite this article:

Srivastava M V, Vishnu V Y. The infamous story of incident stroke and inflamed gall bladder!.Neurol India 2019;67:389-390

\section{How to cite this URL:}

Srivastava M V, Vishnu V Y. The infamous story of incident stroke and inflamed gall bladder!. Neurol India [serial online] 2019 [cited 2019 May 29 ];67:389-390

Available from: http://www.neurologyindia.com/text.asp?2019/67/2/389/258025

\section{Full Text}

The link between gallbladder disease (GD) and stroke has long been recognized, but recently, the relationship has been found to be far more complex. [1] GD, cardiovascular disease (CVD), and stroke are very common public health issues. The current epidemiological transition in low and middle economic countries has pushed the global burden of CVD and stroke higher, accounting for $30 \%$ of global deaths, and will continue to lead the global mortality trend in the future.[1],[2]

The association between GD and CVD/stroke assumes three different domains in current understanding and the description available in the published literature. This association is said to be related to the shared features in the pathophysiological mechanisms, i.e., cholesterol accumulation in the gall bladder as well as arteriosclerosis in the arterial wall.[2] The precipitation of excess cholesterol in bile as solid crystals is required for cholesterol gallstone formation. Stroke and CVD have atherosclerotic plaques as the cornerstone of pathology.

First, in the past studies, GD patients showed an increased prevalence of CVD/stroke risk factors, such as hypertension, diabetes, hyperlipidemia, and chronic obstructive pulmonary disease. Another possible explanation for this association may be shared metabolic pathways.[1],[2] It is reported that low plasma levels of insulin-like growth factor-1 [IGF-1] may lead to the development of both GD and CHD. Patients with a low level of IGF-1 have been reported to be susceptible to altered postprandial gall bladder emptying. This results in prolonged nucleation of monohydrate cholesterol crystals from the supersaturated bile to form macroscopic stones.[1],[2]

Inflammation could also play an important role in the association between these two conditions. High circulating levels of total homocysteine, $\mathrm{C}$ reactive protein, and other proinflammatory mediators have been incriminated in both the conditions. 
The infamous story of incident stroke and inflamed gall bladder! $:<\mathrm{b}>\mathrm{M}$ V Padma Srivastava $<$ sup $>1</$ sup $>$, VY Vishnu $<$ sup $>2</$ sup $>$, $</ \mathrm{b}>$, Neurololy India

Oxidation stress also plays an important role in the development of GD and CVD/stroke.[1],[2]

Many studies indicate that gut microbiota influence the host health.[3],[4] A recent study suggests that altered composition of gut microbiota increase the risk of stroke by derived signaling molecules, and GD is related to microbiota dysbiosis in the gut and biliary tract.[3],[4]

Second, GD is a multifactorial disease with associated risk factors, including gender, age, genetic factors, race, obesity, rapid weight loss, diet, alcohol use, diabetes, hyperlipidemia, drug use, and pregnancy.[1],[2]

Similarly, GD and stroke have certain risk factors in common including gender, age, genetic background, race, obesity, diet, alcohol consumption, diabetes, and hyperlipidemia.[5]

After adjusting for the potential confounding factors, a recent population-based cohort study demonstrated a significant association between GD and increased risk of all strokes, ischemic, and hemorrhagic.[5] GD, therefore, might be a new found risk factor for stroke, including ischemic and hemorrhagic stroke and aneurysmal subarachnoid hemorrhage (SAH).[6], [7] Similarly, Cho et al., reported that in patients presenting with acute cholecystitis, a past history of stroke emerged as a significant independent risk factor. In their study of patients with acute cholecystitis, five independent risk factors, such as age $>60$ years, male sex, presence of CVD, diabetes, and a past history of stroke (odds ratio [OR] of $8.017 ; 95 \%$ confidence interval [Cl] 2.650-24.804), were found. In their report, 84\% of patients with a history of stroke presented with acute cholecystitis versus $32.2 \%$ without a history of stroke $(P<0.001)$. Hence, patients with a history of stroke had an 98 -fold higher risk for the development of acute cholecystitis.[5]

Finally, the third form of association is the occurrence of acute cholecystitis in a patient who presents with acute stroke.[7] This association is certainly rare and not well clarified yet. Acute cholecystitis was reported to follow acute surgical interventions and critical care settings with a variable frequency of $1 \%-4.6 \%$; occurring within a week-to-one month after the preceding incident. The pathology has been hypothesized as a compromise of the circulation to the gall bladder and biliary obstruction due to the concentration of bile. Not many reports exist linking acute cholecystitis to acute stroke. Koizumi et al., reported that of the 252 patients who presented with acute stroke, which included both ischemic and hemorrhagic stroke and SAH, 2.7\% exhibited acute cholecystitis.[8] Ushiyama et al., reported the development of acute cholecystitis in $1.2 \%$ of acute stroke patients. [9] Fukuoka et al., reported $1.4 \%$ of patients with acute ischemic stroke who developed acute cholecystitis. In the majority of studies, acalculous cholecystitis predominates. [7]

This study reports nearly identical findings emphasizing the importance of being vigilant about the development of acute cholecystitis to optimize outcome.[8]

The mechanisms underlying the development of acute cholecystitis after acute stroke have been hypothesized to be ( 1 ) compromised circulation to the gall bladder, and biliary obstruction due to contractile dysfunction as a result of a bed-ridden status; (2) infection caused by gallstones and/or the susceptibility to infection due to the presence of diabetes. Several reports also link the fasting period to the incidence of cholecystitis. This association is likely to be due to the hyposecretion of gastrointestinal hormones such as cholecystokinin, resulting in contractile dysfunction of the gall bladder. Occurrence of autonomic dysfunction in patients with acute ischemic stroke may also cause biliary contractile dysfunction.[7],[9],[10]

It is pertinent to identify the presence of acute cholecystitis and provide suitable treatment in these patients with acute stroke, who otherwise may not be in a position to recognize or complain. Early ambulation and resumption of nutritional intake may also help to prevent the occurrence of acute cholecystitis in patients with acute stroke.

\section{References}

1 Olaiya MT, Chiou HY, Jeng JS, Lien LM, Hsieh FI. Significantly increased risk of cardiovascular disease amongst patients with gallstone disease: A population based cohort study. PLoS One 2013; 8:1-8.

Fan LI, Chen BH, Dai ZJ. The relationship between gallstone disease and cardiovascular disease. Sci Rep

2017; 7: 15104.

Wu T, Zhang Z, Liu B, Hou D, Liang Y, Zhang J, et al. Gut microbiota dysbiosis and bacterial community assembly 
associated with cholesterol gallstones in large-scale study. BMC Genomics 2013; 14:669.

4 Tang WH, Kitai T, Hazen SL. Gut microbiota in cardiovascular health and disease. Circ Res 2017; 120:1183-96.

5 Wei $\mathrm{CY}$, Chung TC, Chen CH, Lin CC, Sung FC, Chung WT, et al. Gallstone disease and the risk of stroke: A nationwide population-based study. J Stroke Cerebrovasc Dis 2014;23:1813-20.

6 Cho JY, Han HS, Yoon YS, Ahn KS. Risk factors for acute cholecystitis and a complicated clinical course in patients with symptomatic cholelithiasis. Arch Surg 2010; 145:329-33.

7 Fukuoka T, Hayashi T, Kato Y, Ohe Y, Deguchi I, Maruyama H, et al. Clinical review of 24 patients with acute cholecystitis after acute cerebral infarction. Intern Med 2014;53:1321-3.

8 Kuroi Y, Imazato D, Yamazaki K, Kasuya H. Acute cholecystitis in patients with stroke. Neurol India 2019;67:439-41.

9 Ushiyama M, Koike J, Zenisaka H, Seguchi K, Ikeda S, Yanagisawa N. Acute acalculous cholecystitis as a complication of cerebrovascular disease. Rinsho Shinkeigaku 1997; 37:218-23.

10 Ushiyama M, Koike J, Zenisaka H, Seguchi K, Ikeda S, Yanagisawa N. Acute acalculous cholecystitis as a complication of cerebrovascular disease. Rinsho Shinkeigaku (Clin Neurol) 1997; 37:218-23. 